2006

\title{
Benefits of On-Line Chat for Single Mothers
}

\author{
Miller, Pamela
}

Haworth Press

Miller, Pamela. (2006). "Benefits of On-Line Chat for Single Mothers". Journal of Evidence Based Social Work Practice, Vol. 3, No. 2: 167-181.

http://hdl.handle.net/1880/44688

Downloaded from PRISM Repository, University of Calgary 


\title{
Benefits of On-Line Chat for Single Mothers
}

\author{
Pam Miller, PhD
}

SUMMARY. This article contributes to the literature on the use of Information Technology (IT) in Human Services by reporting on an evaluation that was conducted of a program that provided computers, private chat software, technical and professional support and Internet access to a group of single mothers to increase their support network through on-line communication. The program proved to be successful on several dimensions and one of the major contributing factors to its success was the anonymous nature of the chat communication. Additional research is advised to look further into the role of anonymity in creating honest and meaningful exchanges in this kind of "electronic" support group. It is one of the characteristics that distinguished this type of support group from traditional support groups and makes this not just a substitute for face-to-face support groups but a unique form of support. doi:10.1300/J394v03n03_12 [Article copies available for a fee from The Haworth Document Delivery Service: 1-800-HAWORTH. E-mail address: <docdelivery@haworthpress.com> Website: <http://www.Haworth Press.com> 102006 by The Haworth Press, Inc. All rights reserved.]

KEYWORDS. On-line chat, peer support, single mothers, Internet communication

Pam Miller is Director of eLearning and Distance Education, Faculty of Social Work, University of Calgary, 2500 University Drive NW, Calgary, Alberta, T2N 1N4, Canada (E-mail: millerp@ucalgary.ca).

[Haworth co-indexing entry note]: "Benefits of On-Line Chat for Single Mothers." Miller, Pam. Co-published simultaneously in Journal of Evidence-Based Social Work (The Haworth Press. Inc.) Vol. 3, No. 3/4, 2006, pp. 167-181; and: Information Technology and Evidence-Based Social Work Practice (ed: Judith M. Dunlop, and Michael J. Holosko) The Haworth Press, Inc., 2006, pp. 167-181. Single or multiple copies of this article are available for a fee from The Haworth Document Delivery Service [1-800-HAWORTH, 9:00 a.m. - 5:00 p.m. (EST). E-mail address: docdelivery@ haworthpress.com].

Available online at http://jebsw.haworthpress.com

(C) 2006 by The Haworth Press, Inc. All rights reserved. 


\section{INTRODUCTION}

The literature on the use of information technology (IT) in health and human services indicates that there is a gap between the use of and information about "best practices" in using information technology in health services compared to what is available in human services. This article contributes to the literature on the use of IT in human services and evidence-based practice by reporting on an evaluation conducted on a program that provided computers, private chat software, technical and professional support and Internet access to a group of single mothers to increase their support network through on-line communication. The program proved successful on several dimensions and one of the major contributing factors to its success was the anonymous nature of the chat communication.

\section{Use of Information Technology in Health and Human Services}

In the literature on health services and technology over the past decade, there is an extensive selection of descriptive articles on various technological applications and interventions primarily from the United States with a growing body of research on their effectiveness. For example, Gerberding, Kukafka, and O'Carroll (2001) et al., reviewed several applications linking public health and clinical practice with information technology in hope of improving service delivery through storing and retrieval of information about clients. One application described was the Cornerstone data system developed in Illinois, which aimed to assist nurses with a means of documenting the expenditure of dollars through identifying how much time was spent with each client being served. Another cited example was the coordination of several federal programs in the United States, through the Department of Health and Human Services, to develop a system for reporting, monitoring, and maximizing the utility of data relevant to patient safety and preventing medical errors in health-care settings.

Some information storing and retrieval systems have been evaluated for their effectiveness in assisting with diagnostic functions. For example, Sibbald (1999) reported on CareVISION (which provides instant access to patient histories, encounters, and lab results) and VON Canada (which tests the use of point-of-care technology through hand-held computers). Initial evaluation of these tools suggests that they provide easy access to client data and quick documentation. Other databases (e.g., Medline) and expert systems (e.g., MYCIN; INTERNIST) make 
the latest medical research readily available to health-care professionals. These programs support such technology initiatives as computer diagnostic programs with evidence supporting significantly increased diagnostic performance (Berner et al., 1994; Berner, Maisiak, Cobbs, \& Taunton, 1999).

Another use of technology in health services has been to enhance the ability of practitioners and clients to connect across sites. Since 1992, for example, the telemedicine program at East Carolina University has conducted over 2,000 medical consultations (32 specialty areas) using a two-way video system (Jones, 1998). These types of systems also facilitate the use of desktop video conferencing for young hospitalized patients to link electronically with their school classmates and teachers. A variety of telecommunication interventions involving telephone as well as videoconferencing are used to assist caregivers of elders with dementia (Wright, Bennet, \& Gramling, 1998). Also, the United States has seen a marked increase (from 46 to 70 ) in the use of tele-psychiatry programs in just a two-year period (Junnaker, 1998). Dakins (1996) noted that there has been a front-line movement by nurses to use telemedicine to deliver care to rural patients in the United States for the past decade.

In addition to describing applications that provide supports for practitioners, the literature in health services indicates that information technology has been used to enable consumers to play a more active role in their own care, including self-care. In the United States, the National Library of Medicine (NLM) provides free access to timely and critical health information. In 1998, it initiated the "Medical Questions? MEDLINE Has Answers" project designed to determine the feasibility of providing consumers access to health information in public libraries (e.g., NLM teams up with public libraries, 1998). A similar on-line project was initiated by Health Canada called the Health Knowledge Network, which is a collection of more than 23 different "centers" designed to link the public to accurate, timely, and Canadian health information.

A prevailing misperception of many health professionals is that primarily their peers use Listservs and newsgroups. However, in reality, the literature in health services indicates that Listservs and newsgroups are useful tools for clients to take charge of their health. For example, MSWatch has a "place" where patients can go to ask a question about their condition. A nurse or physician is "on call" via e-mail. The patient receives a response to concerns within 24 to 48 hours. In addition, the site provides access to other sources of information and support such as participating in on-line discussions or forums with other multiple sclerosis patients as well as having links to educational literature on the disease 
(Sherter, 1998). Bowles and Dansky (2002) reported on the use of tele-video technology to improve the self-management of older diabetic clients. Evaluation of the program suggested that this was a cost-effective strategy. Further, it connected isolated seniors, provided support to caregivers, and improved self-managed care. Along with positive reports on its use, the use of information technology for the delivery of health and human services has also raised concerns. For example, Yasnoff et al. (2001) reported on the American Medical Informatics Association Spring Conference, which brought together public health and informatics communities to develop a national agenda for public health informatics. Invited participants formed two key recommendations: (1) all stakeholders need to be engaged in coordinated activities related to public health information architecture, best practices and standards; and (2) informatics training is needed throughout the public health work force.

Others have also raised the need for standards. For example, Rigby, Forsstrom, Roberts, and Wyatt (2001) reported on the findings from a European study done to investigate the accreditation and certification of telematics services in health. They sought to both identify and quantify the risks attributable to informatics services, and the degree of concern that they produced. In their survey of 54 key informants, $67 \%$ reported they had experienced one or more problems with health telematic services such as telemedicine, drug prescriptions on the Internet, and Web site use. A comparison between the concerns raised in the literature on health services with human service literature along with recommendations for standards could result in identification of concerns and standards, which span professional boundaries.

The literature describing or evaluating the effectiveness of interventions using technology in social work practice is sparse in comparison with that of health services. Social work is beginning to follow the health profession's lead in using information-age technology, such as video conferencing, to enhance and increase access to services (Miller, Kraus, Sprang, \& Burton, 2002). The Consolidated Department of Psychiatry at Harvard Medial School connects specialists, via a video conferencing tool, with social workers working out of a Trial Heath Center in Princeton, Maine. The center, with a staff of six social workers, serves 28 families with 73 children on a native reservation that is larger than the state of Connecticut. Each week, social workers use a videophone to present their cases to a specialist who provides clinical supervision and helps them formulate treatment plans.

Along with describing the use of video conferencing, during the last two decades, the literature in social work has described the current and 
potential impact of other uses of technology on social work and human services. There has been a growing discussion of the impact of information technology on social agency practice along with descriptions of micro-computer use in individual agencies (Hudson, 1993; Pardeck \& Murphy, 1986; Quinn, 1996; Schoech, 1999). Finally, there have also been reports of the use of computer-based information technology with clients, which includes interviewing and assessment, evaluation of practice, education, biofeedback, and decision support (Schoech, 1996). The following section of this article provides a summary of a successful application of information technology to provide support to a group of single mothers in Southern Alberta, Canada.

\section{DESCRIPTION OF PROGRAM: SUPPORTNET}

SupportNet is a program which provides a means, through communication technology, for "at risk" pregnant and parenting women to receive and provide support and information through peer consultation, professional consultation and Internet access. "At risk" in this context is defined as young teens and women, of any age, who are socially isolated, or who experience challenges due to language barriers, low income, low education levels, low social support, single parenting, or cultural isolation (i.e., new immigrants). The program is based on the "Staying Connected" project developed through Dalhousie University in Nova Scotia, Canada.

SupportNet started in 1998 through Better Beginnings, a community-based coalition-directed project that included over 250 agencies, business partnerships and individuals in southwestern Alberta. The participants in SupportNet are provided computers, Internet access, a modem and a software program that enables them to participate in the SupportNet secure chats and e-mail as well as have access to Internet mail and the web. SupportNet chats are stored in an archive so that participants can access them for information at a later time or even if they were not available to participate in the synchronous chat. Professionals are invited by the Program Coordinator to enter the chat room at a prearranged time so that the participants can have access to professional consultation on-line. The Program Coordinator moderates the chats to respond to the needs of the participants, and, in addition, if one or more of the participants "breaks the rules" for engaging in discussion, the Coordinator has the authority to warn and then, if necessary, remove the participant(s) from the program. The Coordinator is also responsible for 
setting up the computers in the homes of the participants and teaching them how to use the chat and other tools provided through software installed on the computer.

\section{EVALUATION PURPOSE AND PROCESS}

\section{Purpose}

In November of 2000, the advisory committee for SupportNet identified the need for an evaluation of the program by an external evaluator, to assess the merits of and identify any issues in the delivery of SupportNet from the perspective of the users. The collection of data for this evaluation was conducted during December 2000 and the analyses of data completed early January 2001.

\section{Process}

The software used by SupportNet has a tool for developing and providing surveys to its participants. The Program Coordinator regularly uses this tool for ongoing feedback from participants on their experiences with the chats. The Coordinator gave the evaluator an orientation to the tool after setting up the software on her computer and giving her an account so that she could use the survey to query the participants for the evaluation. Participants were asked, through e-mail, to respond to the questions within a two-week period, and because they use fictitious usernames for SupportNet, they cannot be identified. The Coordinator downloaded their responses to the survey and sent them to the evaluator through e-mail. Since the program does not allow anyone to alter responses to questions, the Coordinator could not alter them if she disagreed with them. Respondents were also invited to enter a chat with the evaluator one week and then two weeks after the survey was posted.

There were three respondents who participated in the first chat, which lasted about 30 minutes and five in the second chat, which lasted almost an hour. The average number of participants who participate per chat is around five so the evaluator had a good participation rate in the two chats that were conducted. The evaluator used responses to the survey for further probes during the chats about the respondents' experiences of SupportNet. The chats were saved on the evaluator's computer so that she was able to print them out and analyze them for major themes. Data from the survey was analyzed using percentages, charts 
and tables. The following is a summary of the findings from both the survey and chats.

\section{EVALUATION RESULTS}

\section{Description of the Sample}

Eighteen $(\mathrm{N}=18)$ of 30 SupportNet members in 2001 responded to the voluntary on-line survey. They ranged in age from 17 to 34 years old with an average age of nearly 24 . Sixteen had at least one child, two were pregnant with their first child, and six members had two or more children. Ages of their oldest children ranged from nine weeks to 12 years with the average being just over three years. The six women who had more than one child reported that their youngest was between three weeks old to four years old. In all, five members were pregnant-all in the last half of their pregnancies. Six had not yet completed high school, seven had high school diplomas, and four other respondents had attended some college courses. The length of time respondents had been SupportNet participants ranged from three weeks to 12 months with the average membership tenure being just over four months. A little more than half of those responding had been members for three months or less. See Figure 1.

\section{Perception of Benefits Gained from SupportNet}

One set of survey questions dealt with how SupportNet members perceived benefits gained in particular areas. Participants were asked to respond to statements such as "I have more people to turn to because of SupportNet," "I have gained useful information about child care because of SupportNet," and "I have increased my confidence about dealing with my child (children) as a result of SupportNet." Results were overall very positive. In fact, there was only one "disagree" response and one "strongly disagree" response in the 72 responses. Those who responded "unsure" tended to be those who have been on SupportNet for three or four months. See Figure 2.

During the two chats, as a follow-up to the survey questions about benefits, the respondents were asked to "talk" to me about whether SupportNet made a difference in their lives and, if so, how. In both chats the participants indicated that SupportNet provided them a way to meet people, get advice, get resources from the Internet, vent frustrations and 
FIGURE 1. Number of Months Participants Have Been on SupportNet

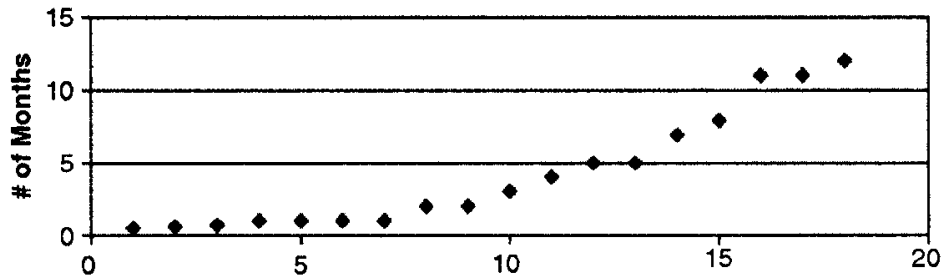

Eighteen Respondents

FIGURE 2. Benefits of SupportNet

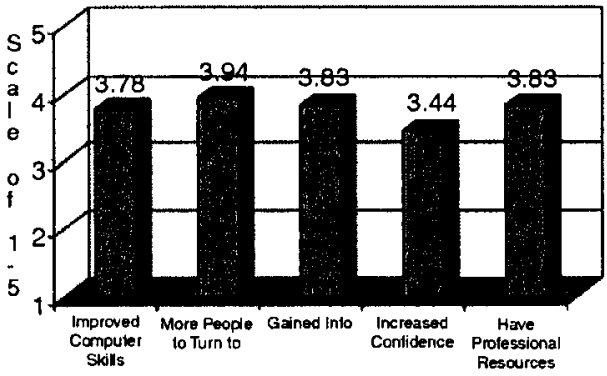

worries, as well as providing other benefits. One participant stated that "it gives an outlet to the rest of the world" while another stated that "without it I would feel more isolated." One participant stated that because of her chats in SupportNet "I value the time I spend with my son more." One participant indicated that she liked SupportNet because "It helps me meet people and I can ask the girls for advice and they help me out and I like checking my e-mail so I can keep in touch with my parents in Ontario." Using SupportNet to connect not just with the other "girls" but also with family and friends through Internet chat was mentioned three times during my two chats. Accessing the Internet for resources was mentioned four times and the most noted benefit was overwhelmingly the ability to meet and talk with people who shared the same experience as the participants. This benefit was identified 10 times during my two chats. 
Along with talking with people who share the same experience, the other most frequently identified benefit was the anonymity provided by SupportNet. Participants used fictitious usernames so they did not know each other's identity. If they choose they can e-mail each other privately and reveal their identities, but this was not required, and if the participants chose to reveal themselves to another participant, it was in order to have a further contact outside of the chat and e-mail forms of communication. [I was told by the Coordinator that this has not been done by many participants].

Anonymity was identified six times as an "important benefit" of SupportNet. One participant stated that it was better than face-to-face support groups because, "You don't have to worry what the other person thinks of you." Another participant stated, "I can get my feelings out better on the computer than talking about it with someone face-to-face." A third participant stated, "We can talk about anything with each other and none of us know who we are on the outside." A fourth participant said that she felt the most important benefit of SupportNet was "talking to girls I don't know, I can tell them anything." A fifth participant noted, "Sometimes it is easy to speak with somebody you don't know. I mean, it's more easy, at least for me."

\section{Staff Support}

The staff support provided by SupportNet received high marks. When asked to respond to the statement "SupportNet staff members have been helpful and supportive," eight women strongly agreed (44\%), seven agreed (39\%) and the three who were unsure (17\%) had only been members one month or less. Fifteen respondents $(83 \%)$ agreed or strongly agreed that the training they received made them comfortable with using SupportNet services. A slightly fewer number, thirteen (68\%), agreed or strongly agreed with the statement "problems or difficulties I have had were dealt with to my satisfaction."

During the chat session, the participants were asked if it was helpful to have the Program Coordinator monitor the chats and the response was that: "If there is fighting then someone should tell sysop (this is the username in the chat for the Program Coordinator) because we don't need it, this is a support group." The participants felt the Coordinator, therefore, provided a useful role in keeping the chat civil and free from unnecessary arguments. 


\section{Overall Satisfaction}

When participants were asked to respond to the summarizing statement "My overall satisfaction with SupportNet is," 10 said they were very satisfied, six were satisfied and two new SupportNet members (one month or less) said they "didn't know." Twelve participants (67\%) learned of SupportNet through Better Beginnings, five heard of SupportNet from a friend and one from a teacher. All $(100 \%)$ would recommend SupportNet to a friend.

When asked to be specific about what they found most valuable about SupportNet, the women said the contact with others in similar circumstances and information from experts (i.e., nurses) were most valuable. This was supported by their comments during the chats as described in the summary of findings in the Benefits sub-section.

When asked to name something that was least valuable, $15(83 \%)$ could not think of anything. One person said the Internet was least valuable, one person said that being helpful to others was least valuable and one person simply stated that she didn't have a lot of time to be on it. When participants were asked if the training enabled then to be more comfortable with SupportNet services, $22 \%$ reported that they strongly agreed, $61 \%$ reported that they agreed, and $17 \%$ were unsure about whether the training helped them to feel more comfortable. When asked if problems/difficulties were dealt with to their satisfaction, $11 \%$ strongly agreed, $67 \%$ agreed and $22 \%$ were unsure about their satisfaction with problem resolution.

The following were cited as the agencies and/or professionals as well as general areas of interest that respondents either found information about through SupportNet or already knew about and use as a result of SupportNet: Baby center, Parenting page, ADHD, Dietician, Single parent center, Children's center, Parent, Human resources webpage, Alcohol abuse resources, Prenatal nurse, Home nurse, Counselor, Day care homes, Teachers, Government page, Child abuse resources, Better Beginnings, Nurse Lawyer, Health nurses on-line.

When asked to list the area of SupportNet that they most frequently used, 12 women listed more than one area. In fact, one person said "all." Eleven people put SupportNet Chat first in their list. See Figure 4.

Professionals Online is a monthly feature of SupportNet and while eight people responded that this feature has been helpful, 10 women said that they had not used it yet. During the chats, three participants stated that their contact with professionals in the chats was helpful but they stated that what they found most helpful was connecting with other 
FIGURE 3. Overall Satisfaction with SupportNet

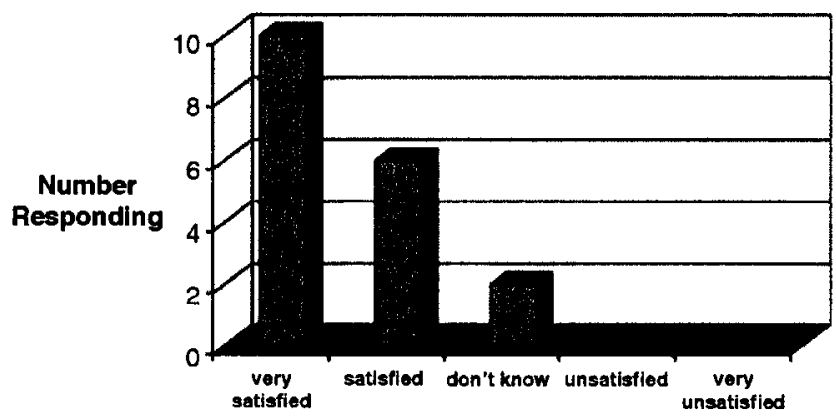

FIGURE 4. Areas of SupportNet Most Frequently Used

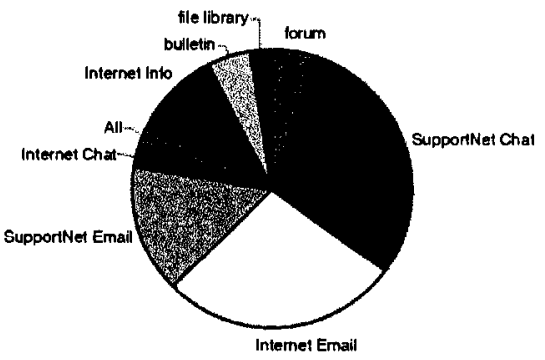

"girls" who were in the same situation as they were in. Two participants in the chats stated that they would like to have more professionals participate in the chats but again they did not see this as necessary in terms of what they found most beneficial (i.e., contact with other mothers).

When asked what suggestions they had for improving SupportNet, $12(67 \%)$ were happy with SupportNet as it is and have no suggestions for improvement. The following suggestions made by other respondents were: (1) post pictures of newborns, (2) get more people to talk online (2 people voiced this opinion), (3) post something on fetal development, (4) to know how to get into chats when the nurses are on, and (5) putting the parenting courses on-line. During the chats, the most frequently mentioned area for improvement was to stabilize the connections during the chats. All of the participants who participated in the 
chats with the evaluator mentioned that they had been disconnected at least once during a chat. All participants "said" that when they were disconnected they just reconnected and continued in the chat room. So, although it was an annoyance it did not deter them from participating in SupportNet Chat.

\section{RECOMMENDATIONS}

It was clear that the respondents in this evaluation felt that they were benefiting from SupportNet and the primary benefit for them was the connection SupportNet provides with people who they perceive to be in similar situations as themselves. Another important benefit was the connection with the Internet that SupportNet provided so respondents can access resources on the Web as well as connect with friends and relatives through Internet e-mail. It is also clear that anonymity was a characteristic of the chat communication that was deemed important to these respondents. It allowed them to disclose feelings, concerns, worries, and questions that they might feel uncomfortable sharing face-to-face. These respondents did not cite a connection with professionals as essential, but a few voiced an interest in having increased access to professional consultation through SupportNet.

The only improvement that the respondents in the chats identified as important for SupportNet was stabilizing the chat connection so they were not interrupted by having to reconnect when the connection was broken. The respondents in the survey had more recommendations for SupportNet but these were not identified as essential, rather they were offered as suggestions for enhancing the program.

Given these findings, it seems as if this program is meeting the goal of the program in providing a means for "at risk" pregnant and parenting women to receive and provide support and information through peer consultation, professional consultation and Internet access. Given the lower ratings of professional consultation in this evaluation, staff may want to focus on developing mechanisms for including professionals in chats in a way that will be interesting and stimulating for their participants. Another area that certainly is an area of concern is the technology, i.e., quality of connections for participants in the chats. Staff should examine current technology with a view of enhancing or upgrading what is currently available to participants.

Finally, anonymous peer connections through SupportNet have been identified by the respondents as the strongest asset of Support- 
Net and additional research is probably advised to look further into the role of anonymity in creating honest and meaningful exchanges in this kind of "electronic" support group. It is one of the characteristics that distinguishes this type of support group from traditional support groups and makes this not just a substitute for face-to-face support groups but also a unique form of support. Since this evaluation was conducted Support-Net has continued to provide service to single parents and as of the summer of 2004 is at its capacity with 50 participants.

\section{Practitioner/Provider Questions}

1. The respondents in this evaluation seem to indicate that for many of them peer consultation was more important than consultation with professionals; what questions would you like to address to examine this further?

2. The evaluator makes a claim that "electronic" support groups provide a unique form of support and they should not be looked at as just a substitute for face-to-face support. In terms of "best practice," are there individuals who you think would benefit from "electronic" support groups more than from face-to-face support groups?

3. Connectivity breakdowns occurred often during SupportNet chats, yet the participants indicated that although the breakdowns were a nuisance they did not diminish their positive view of the benefits of chats. What questions should we address about e-practices, such as SupportNet, when developing best practices?

\section{Consumer/Client Questions}

1. Are you currently using electronic communication to access resources important to you; if yes, what tools do you use, how do you use them, and what is your experience?

2. If you do not currently have access to electronic communication tools, such as e-mail and internet access, would there be a benefit to you of being able to access such tools and, if yes, how would you use them?

3. Would you participate in an electronic support group such as SupportNet? If yes, how would it benefit you and if not, what would be your reasons for declining?

\section{REFERENCES}

Berner, E.S., Webster, G.D., Shugerman, A.A., Jackson, J.R., Algina, J., Baker, A.L., Ball, E.V., Cobbs, C.G., Dennis, V.W., \& Frenkel, E.P. (1994). Performance of four computer-based diagnostic systems. New England Journal of Medicine. 330, $1792-6$.

Berner, E.S., Maisiak, R.S., Cobbs, C.G., \& Taunton, O.D. (1999). Effects of a decision support system on physicians' diagnostic performance. Journal of the American Medical Informatics Association. 6, 420-427.

Bowles, K.H., \& Dansky, K.H. (2002). Teaching self-management of diabetes. Home Healthcare Nurse, 20, 36-42. 
Burke, L., \& Weill, B. (2000). Information technology for the health professions. Upper Saddle River, NJ: Brady/Prentice Hall Health.

Dakins, D.R. (1996). Nurses Nurture Rural Health Networks. Retrieved April 2, 2003 from http://www.telemedmag.com/db_area/archives/1996/960801ru.htm

Finn, J. (1993). An exploration of computer-based self-help/mutual aid groups. In B.

Glastonbury (Ed.) Human Welfare and Technology: Papers from the HUSITA III Conference in Information Technology and the Quality of Life and Services, Assen: Van Gorcum, 70-79.

Finn, J. (1988). Microcomputers in private, nonprofit agencies: A survey of trends and training requirements. Social Work Research and Abstracts, 24(1), 10-14.

Finn, J., \& Lavitt, M. (1994). Computer-based self-help/mutual aid groups for sexual abuse survivors. Social Work with Groups, 17(1), 5-12.

Fishman, D.J. (1997). Telemedicine: Bringing the specialist to the patient. Nurse Management, 28(7), 30-32.

Fox, N.J., Dolman, E.A., Lane, P., O’Rourke, A.J., \& Roberts, C. (1999). The WISDOM project: Training primary care professionals in informatics in a collaborative 'virtual classroom.' Medical Education, 33, 365-370.

Hudson, W.W. (1993). The future of social service computing. Computers in Human Services, 10(2), 1-8.

Johnson, S. (1987). Nonprofit and Public Service Telecomputing. Paper presented at the First International Human Service Information Technology Applications Conference. Birmingham, England. September.

Jones, G. (1998). Telemedicine Program East Caroline University School of Medicine. Retrieved June 3, 2003 from http://www.telemed.med.ecu.edu/r folder/consult.htm Junnakar, S. (1998). Technology Extends Reach of Aid for the Troubled. The New York Times, April 9, 1998.

Karras, B.T., O'Carroll, P., Oberle, M.W., Masuda, D., Lober, W.B., Robins, L.S., Kim, S., Schaad, D.C., \& Scott, C.S. (2002). Development and evaluation of public heal th information at University of Washington. Journal of Public Health Management Practice, 8(3), 37-43.

Kinsella, A. (1997). Telehealth and home care nursing. Home Healthcare Nurse, 15(11), 796-797.

Kukafka, R., O’Carroll, P.W., Gerberding, J.L., Shortliffe, E.H., Aliferis, C., Lumpkin, J.R., \& Yasnoff, W.A. (2001). Issues and opportunities in public health informatics: A panel discussion. Journal of Public Health Management Practice, 7(6), 31-42.

Madera, E.J. (1991). Mutual Aid Self-Help on-line: The New Telecommunities. Paper presented at the International Conference on Computer Technology and Human Services in the 90's: HUSIYA II, Rutgers University, NJ.

Miller, P., \& Hodson Carlton, K. (1999). Asynchronous communication technology tools in practice-future and current uses. Computers in Nursing, 17(4), 162-166.

Miller, P., \& Hodson Carlton, K. (1998), Synchronous communication technology tools in practice-future and current uses. Computers in Nursing, 16(4), 303-307.

Miller, P., \& Hodson Carlton, K. (1998). Technology as a tool for health care collaboration. Computers in Nursing, 16(1), 27-30.

Miller, T.W., Kraus, F.F., Kaak, A., Sprang, R., \& Burton, D. (2002). Telemedicine: A Child Psychiatry Case Report. Telemedicine Journal and eHealth, 8, 135-138. 
Pardeck J.T., \& Murphy, J.W. (1986). Microcomputer technology in clinical social work practice: Benefits and problems. Arete, 11 (1), 35-43.

Puskin, D.S., Mintzer, C.L., \& Wasem, C. (1998). Telemedicine: Building Rural Systems for Today and Tomorrow. Retrieved May 25, 2003 from http://www.nal. usda.gov/orhp/chapter.htm

Quinn, S. (1996). HyperResearch. Computers in Human Services, 13(3), 91-95.

Raffoul, P.R., \& McNeece, A.C. (1996) Future issues for social work practice. Boston, MA: Allyn and Bacon.

Reese, B. (1998). Videoconferencing. Retrieved on May 14, 2003 from http://www. credible.com/randoma2.html

Rigby, M., Forsstrom, J., Roberts, R., \& Wyatt, J. (2001). Verifying quality and safety in health information sciences. British Medical Journal, 323, 552-556.

Schoech, R. (1999). Human services technology. Binghamton, NY: The Haworth Press, Inc.

Schoech, R. (1996). Performance support systems: Integrating information technology under practitioner control. Computers in Human Services, 13(3), 1-18.

Sheil, E.P., \& Wierenga, M.E. (1994). The use of the Nursing Minimum Data Set in several clinical populations. In S.J. Grobe \& E.S.P. Pluyter-Wenting (Eds.). Nursing informatics: An international overview for nursing in a technical era, Proceedings of the Fifth IMIA International Conference on Nursing Computers and Information Science (pp. 129-143). New York, NY: Elsevier.

Sherter, A.L. (1998). Provider automation: Breaking new ground. Health Data Management, $6(2), 134-138$.

Sibbald, B. (1998). NLM teams up with public libraries to help consumers find medical answers. NLM Newsline, 53(3+4), 15 .

Sibbald, B. (1999). Nursing informatics. Canadian Nurse, 94(4), 22-30.

Woolley, D.R. (1998). The Future of Web Conferencing. Retrieved June 6, 2003 from http://thinkofit.com/webconf/wcfuture.htm

Wright, L.K., Bennet, G., \& Gramling, L. (1998). Telecommunication interventions for caregivers of elders with dementia. Advanced Nursing Science, 20(3), 76-88. Yasnoff, W.A., Overhage, M., Humphreys, B.L., LaVenture, M., Goodman, K.W., Gatewood, L., Ross, D.A., Reid, J., Hammond, W.E., Dwyer, D., Huff, S.H., Gothman, I., Kukafka, R., Loonsky, J.W., \& Wagner, M.M. (2001). A national agenda for public health information. Journal of Public Health Management Practice, $7(6), 1-21$. 